\title{
O Impacto da Disputa Comercial entre os Estados Unidos e a China no Agronegócio Brasileiro
}

\section{The Impact of Commercial Dispute between The United States and China in Brazilian Agribusiness}

\author{
Elisangela Gelatti ${ }^{\mathrm{a}}$ \\ Daniel Arruda Coronel ${ }^{\mathrm{b}}$ \\ Angelo Costa Gurgel ${ }^{c}$ \\ Paulo Ricardo Feistel ${ }^{b}$ \\ Maiara Thais Tolfo Gabbi ${ }^{a}$
}

\begin{abstract}
Resumo: Este estudo tem como objetivo analisar o impacto da disputa comercial entre os Estados Unidos e a China no agronegócio brasileiro. Para isso, realizam-se duas simulações a fim de se analisar o impacto nos fluxos comerciais (produção, exportações, importações, preços e bem-estar) do setor, através do modelo de equilíbrio geral computável (MEGC), mais especificamente o Global trade analysis project (GTAP). Dentre os resultados, é possível destacar que os impactos econômicos para os valores das exportações do agronegócio brasileiro são positivos apenas para o setor de grãos, pois, na primeira simulação, com proteção comercial parcial, observa-se uma variação positiva de $9,86 \%$ e, na segunda simulação de uma disputa comercial entre China e Estados Unidos com proteção comercial completa, observa-se uma variação positiva de 6,40\%, evidenciando que o setor de grãos obtém ganhos de comércio. Esses ganhos provêm do declínio acentuado do comércio bilateral entre China e Estados Unidos e de um aumento por importações para os seus terceiros parceiros comerciais, como, neste caso, o Brasil, exportando mais grãos para a China. No entanto, para os demais setores analisados do agronegócio, os resultados obtidos dos cenários propostos, em ambas as simulações, são negativos, sendo prejudicial aos setores como frutas e legumes, cana-de-açúcar e outros, pecuária e carnes e produtos agroindustriais, nos quais é possível verificar uma redução na produção do agronegócio brasileiro. Esse efeito negativo vem do deslocamento de recursos produtivos (terra, capital e trabalho) dos vários setores agropecuários em direção ao setor de grãos, que é o principal setor de exportação do Brasil para a China e compete diretamente com os Estados Unidos nesse mercado.
\end{abstract}

Palavras-chave: agronegócio; comércio internacional; modelo de equilíbrio geral

a Escola Superior de Agricultura "Luiz de Queiroz" (Esalq) - Universidade de São Paulo (USP), Departamento de Economia. Piracicaba, São Paulo, Brasil.

b Universidade Federal de Santa Maria (UFSM), Departamento de Economia. Santa Maria, Rio Grande do Sul, Brasil.

c Escola de Economia de São Paulo (EESP) - Fundação Getulio Vargas (FGV), Departamento de Economia. São Paulo, São Paulo, Brasil. 
computável.

Abstract: This study aimed to analyze the impact of the commercial dispute between the United States and China, in Brazilian agribusiness. In this sense, two simulations were carried out to analyze the impact on the commercial flows (production, exports, imports, prices and well-being) of the sector, through the computable general equilibrium model (MEGC), more specifically the Global Trade Analysis Project (GTAP). Among the results, it was possible to highlight that the economic impacts for the export values of Brazilian agribusiness would be positive only for the grain sector, because, in the first simulation, with partial commercial protection, we observed a positive variation of $9.86 \%$ and, in the second simulation of a commercial dispute between China and the United States with complete commercial protection, we observed a positive variation of $6.40 \%$, evincing that the grain sector obtains gains from trade. These gains come from decline of bilateral trade between China and the United States and an increase in imports for their third trade partners, as in this case, Brazil, exporting more grains to China. Nevertheless, for the other agribusiness sectors analyzed, the results obtained from the proposed scenarios, in both simulations, are negative, being harmful to the sectors as fruit and vegetables, sugar cane and others, livestock and meat and agroindustry products, in which it is possible to verify a reduction in production of Brazilian agribusiness. This negative effect comes from the displacement of productive resources (land, capital, labor) of the several agricultural and livestock sectors in direction to the grain sector, which is the main sector of exports from Brazil to China and competes directly with the USA in this market.

Keywords: agribusiness; international trade; computable general equilibrium model.

JEL Classification: F14; Q17; C68.

\section{1 lntrodução}

As disputas comerciais entre os Estados Unidos e a China têm atraído cada vez mais a atenção e preocupação sobre seus possíveis impactos na economia global. Ambos os países são as maiores economias do mundo, representando cerca de $40 \%$ da economia global, e responsáveis por aproximadamente $23,8 \%$ das exportações mundiais de mercadorias de bens e serviços (WORLD BANK, 2018).

Essas disputas se intensificaram a partir do anúncio do governo americano de impor tarifas adicionais sobre um conjunto de produtos chineses, com a estratégia de reduzir o déficit comercial e proteger o mercado com base em questões relacionadas aos direitos de propriedade intelectual, cujos objetivos são evitar transferências de tecnologias e diminuir o desemprego dos Estados Unidos (WHITE HOUSE, 2018). Em resposta, o governo chinês anunciou medidas de política comercial, adotando tarifas similares aos produtos importados dos Estados Unidos. 
Em julho de 2018, o presidente dos Estados Unidos assinou a primeira ordem para impor tarifas não específicas para os países com que realiza comércio, em especial para a China, com $25 \%$ sobre o aço e $10 \%$ sobre o alumínio (WHITE HOUSE, 2018). Em resposta a essas tarifas, a China suspendeu obrigações de redução de tarifas em produtos de origem norte-americana, tendo, como efeito imediato, uma tarifa adicional de $25 \%$, que contempla produtos como soja, milho, trigo, sorgo, carnes suínas e bovina, café, algodão, entre outros (WORLD TRADE ORGANIZATION, 2018).

A decisão da China de contestar as sobretaxas elevando as tarifas de importação aos produtos agropecuários americanos pressionará sua busca por novos parceiros comerciais a fim de garantir a segurança alimentar de sua população, visto que é o país mais populoso do mundo, possuindo 1.386 bilhões de habitantes, e sua produção interna não é suficiente para atender sua demanda por alimentos. Necessitando de um grande volume de produtos agrícolas, a China poderá ampliar suas relações comerciais com países como União Europeia, Brasil, Canadá e Indonésia (WORLD TRADE ORGANIZATION, 2018).

O Brasil é uma das nações que se destaca no mercado internacional como o terceiro maior exportador de produtos agrícolas, visto que, em 2017, o país exportou US $\$ 88$ bilhões, resultando em um crescimento de 14\% em relação ao ano anterior, ficando atrás da União Europeia (US\$ 647 bilhões) e dos Estados Unidos (US $\$ 170$ bilhões) (WORLD TRADE ORGANIZATION, 2018). Os produtos brasileiros exportados que mais tiveram demanda foram soja, carnes e café (AGROSTAT, 2019). Convém ressaltar que a soja correspondeu a 116,99 milhões de toneladas exportadas (safra 2017-2018), garantindo ao Brasil o título de segundo maior exportador do mundo dessa commodity, sendo o primeiro os Estados Unidos, com 119,51 milhões de toneladas (EMPRESA BRASILEIRA DE PESQUISA EM AGROPECUÁRIA, 2018).

Contudo, essa disputa comercial entre os Estados Unidos e a China, seguida por suscetíveis respostas de retaliação entre os países, causa riscos para o comércio global, principalmente para o agronegócio brasileiro, um setor estratégico para a garantia da segurança alimentar mundial, o qual está exposto aos possíveis impactos das mudanças de preços e produção das commodities, maiores volatilidades nas taxas de câmbio efetivas nominais, incertezas de mercado, mudanças nos níveis de renda e possíveis desequilíbrios da economia mundial (UNITED NATIONS CONFERENCE ON TRADE AND DEVELOPMENT, 2019).

Diante da relevância do setor do agronegócio brasileiro, essas disputas comerciais entre Estados Unidos e China poderão trazer oportunidades ou desvantagens para o setor. Então, com base nisso, o problema desta pesquisa consiste em responder à seguinte questão norteadora: em que magnitude as disputas co- 
merciais econômicas entre os Estados Unidos e a China afetarão o agronegócio brasileiro?

Com base nessa temática, este estudo tem como objetivo analisar o impacto da disputa comercial entre os Estados Unidos e a China para o agronegócio brasileiro. Para tal, utiliza-se metodologicamente simulações em dois cenários, analisando-se o impacto nos fluxos comerciais (produção, exportações, importações, preços e bem-estar) do agronegócio brasileiro a partir de um modelo de equilíbrio geral computável (MEGC), mais especificamente, o Global trade analysis project (GTAP), versão 9.

Disputas e conflitos comerciais interferem de modo negativo no comércio internacional, principalmente se ocorre retaliação por meio dos direitos compensatórios, derivados de práticas protecionistas entre parceiros comerciais (THORSTENSEN, 1998). Considerando-se a importância do comércio internacional para as economias nacionais e avaliando-se a atual disputa comercial entre as maiores economias do mundo, Estados Unidos e China, o estudo busca contribuir para a formulação de políticas econômicas que possam direcionar as relações à liberalização comercial e à ampla interação entre as economias. Por fim, outras contribuições deste estudo estão relacionadas a uma melhor inserção do setor do agronegócio brasileiro no comércio internacional.

O artigo está organizado em cinco seções, iniciando por esta introdução. Na segunda, encontra-se uma revisão dos recentes estudos empíricos com o uso do MEGC-GTAP. Na terceira, apresenta-se a metodologia para o estudo. Na quarta, discutem-se os resultados. Por fim, na quinta seção, alinhavam-se as considerações finais.

\section{Revisão Empírica de Estudos}

Os MEGC são utilizados para analisar o bem-estar econômico e os efeitos de políticas cujos impactos podem ser transmitidos para diversas regiões do mundo (WING, 2004) e têm sido cada vez mais utilizados para o estudo das mais diferentes questões econômicas (CURZEL, 2011).

Gonçalves et al. (2018) avaliam o impacto da atual disputa comercial entre os Estados Unidos e a China usando o MEGC, versão 9 do GTAP. Os autores simulam quatros cenários: a) tarifas dos Estados Unidos sobre as importações chinesas de aço e alumínio; b) tarifas retaliatórias chinesas sobre produtos agrícolas selecionados norte-americanos; c) tarifas retaliatórias dos Estados Unidos sobre produtos manufaturados selecionados dos chineses; e d) tarifas retaliatórias chinesas sobre produtos agrícolas e industriais selecionados dos Estados Unidos. Os autores avaliaram que, no primeiro cenário, são pequenos os efeitos que ocorrem no bem-estar dos países, no entanto são positivos para os Estados Unidos e negativos para a China. No segundo cenário, quando ocorre a retaliação da China, os efeitos no 
bem-estar são negativos tanto para a China quanto para os Estados Unidos. Já no terceiro cenário, os efeitos no bem-estar são positivos para os Estados Unidos e negativos para a China, e os autores indicam que estão ocorrendo tensões comerciais entre os países. Por fim, no quarto cenário, os efeitos no bem-estar são negativos tanto para os Estados Unidos quanto para a China, uma vez que toda ação de imposição de tarifas de um país é acompanhada por resposta de ações retaliatórias do outro país com o qual se realiza comércio. Assim, com essas simulações, as disputas comerciais estariam afetando negativamente o bem-estar global, com a China perdendo a maior parte dessa disputa com os Estados Unidos.

Taheripour e Tyner (2018) analisam as consequências econômicas de uma tarifa chinesa de $25 \%$ sobre soja, trigo, milho, sorgo e carne bovina dos Estados Unidos. Para isso, utilizam o MEGC GTAP-BIO (modelo adaptado pelo GTAP versão 9, utilizando elasticidades para análises de longo prazo). Os resultados encontrados apontam que as tarifas chinesas poderiam reduzir significativamente a produção de soja dos Estados Unidos e aumentar a produção de soja no Brasil, no resto da América do Sul e na própria produção chinesa. A produção de sorgo dos Estados Unidos também declina. Assim, os autores ressaltam que os resultados da simulação examinados mostram que a tarifa chinesa de $25 \%$ é uma proposição perde-perde para a China e para os Estados Unidos. A perda de bem-estar econômico é aproximadamente a mesma em ambos os países. Já o Brasil vê um aumento significativo na produção de soja e uma melhoria no bem-estar econômico.

Rosyadi e Widodo (2017) analisam os impactos do aumento da tarifa, proposta pelo presidente dos Estados Unidos, Donald Trump, contra a China na economia global mediante o MEGC (versão 9 do GTAP). Como resultado, os autores observaram que, ao ser implantada a política de aumento de tarifas pelos Estados Unidos em retaliação à China, causaria um declínio no PIB dos Estados Unidos e da China, no entanto a China sofreria um impacto negativo maior, além dos efeitos negativos de bem-estar para todos os países-membros. Os fenômenos de desvio de comércio estiveram presentes nos resultados da simulação, prevendo declínio acentuado do comércio bilateral entre os dois países e o aumento das exportações para os seus terceiros parceiros comerciais. Os resultados dessa simulação mostram que o objetivo de recuperar a economia americana não será alcançado através da imposição de tarifas de importação. Em vez de melhorar a condição econômica dos Estados Unidos, a pesquisa mostrou que levará a um efeito negativo para a economia desse país. Somente as indústrias têxtil e de vestuário apresentaram um impacto de aumento de produção, pois é o único setor que irá se beneficiar dessa política.

Moretto et al. (2017), usando o MEGC, na versão 9 do GTAP, analisam as oportunidades de comércio de uma possível integração comercial do Brasil com a China. Os resultados revelaram dois benefícios para o Brasil com a formação dessa 
integração. O primeiro seria a mudança do atual perfil de comércio bilateral, em que o país exporta commodities e importa produtos de média e média-alta intensidade tecnológica da China. A simulação mostrou que haveria crescimento do comércio bilateral principalmente de produtos de baixo e médio-baixo conteúdo tecnológico, o que estimularia a produção industrial brasileira. O segundo ganho estaria associado ao aumento do bem-estar, especialmente por causa da maior eficiência alocativa. Embora abaixo do ganho obtido pela China, o valor chegaria a US $\$ 2.373$ milhões.

Os estudos apresentados pelo MEGC são relevantes para a discussão dos impactos causados pelas diversas políticas comerciais para a economia mundial. No entanto, percebe-se a necessidade na literatura de se aprofundar estudos em torno de políticas de disputas comerciais (protecionistas) entre países para identificar quais são seus efeitos (causas e consequências) para o crescimento econômico global, em especial para a economia brasileira, uma vez que, ao ocorrerem esses confrontos comerciais e ações de políticas bilaterais, estas são suscetíveis de serem contrabalançadas por ações de políticas adicionais retaliatórias, além de seus impactos se espalharem para outros países, resultando em efeito em cascata e causando políticas comerciais distorcidas entre países e/ou parceiros econômicos.

\section{Metodologia}

Essa seção tem por objetivo descrever os procedimentos e métodos utilizados. Primeiro, apresenta-se o modelo GTAP (Global Trade Analysis Project) e como ele se encontra estruturado. Após, apresenta-se a fonte e a agregação dos dados, a construção dos cenários analíticos, seguido das elasticidades de substituições e o fechamento do modelo.

\subsection{Global Trade Analysis Project (GTAP)}

O GTAP ${ }^{1}$ é um modelo de equilíbrio geral multirregião, multissetorial e computável, com concorrência perfeita e retornos constantes de escala (WALMSLEY; AGUIAR; NARAYANAN, 2012). Esse modelo permite estimar o impacto de políticas comerciais econômicas internacionais, capturando os resultados dessas políticas e suas relações de interdependência setorial de todo o sistema econômico de forma simultânea (VILELA, 2012).

O GTAP é composto por três módulos centrais. O primeiro é um banco de dados com matrizes de insumo-produto, impostos, contabilidade social, entre ou-

1 O GTAP foi desenvolvido por Thomas Hertel, em 1992, com o objetivo de diminuir os custos de entrada para realizar análises quantitativas de questões econômicas no âmbito mundial. 
tros aspectos, que fornece a base empírica do modelo. Essas matrizes mostram um retrato da economia mundial no que diz respeito aos fluxos de renda entre agentes econômicos intrarregionais e internacionais, volumes de comércio internacional, barreiras tarifárias aplicadas e fatores de produção existentes (FEIJÓ; ALVIM, 2010). Os dados utilizados são empíricos, assegurando a consistência das identidades contábeis do GTAP (VILELA, 2012).

O segundo módulo é uma estrutura aninhada formada por funções microeconômicas tradicionais, como minimização de custo, maximização de lucro, condições de equilíbrio, entre outros, que operacionaliza o banco de dados para a simulação, criando os canais de ação dos choques. Por último, considera um fechamento macroeconômico que determina as variáveis endógenas e exógenas de modo a tornar viável a resolução das equações estruturais do modelo (FEIJÓ; ALVIM, 2010).

O funcionamento de uma economia, no modelo GTAP, é exposto por meio da análise de uma região específica que se relaciona com outras, via cenários do modelo, em que uma variável endógena desse modelo de equilíbrio geral é exposta a choques tarifários ou tecnológicos, por exemplo, para analisar como os setores seriam afetados (MORETTO et al., 2017). Os cenários submetidos a esses choques acabam provocando um "desequilíbrio" no modelo. Assim, para o "[...] modelo atingir um novo equilíbrio, é preciso que ocorram mudanças em variáveis endógenas das equações do modelo [...]" (FEIJÓ; ALVIM, 2010, p. 8).

O sucesso do modelo do GTAP está fortemente relacionado à base de dados global. Esta combina detalhes bilaterais, dados sobre comércio, transporte e proteção que caracterizam os vínculos econômicos entre as regiões e bases de dados individuais de entrada e saída do país que representam as ligações intersetoriais dentro das regiões (HERTEL, 1997).

A base de dados do GTAP encontra-se na versão 9, que representa a economia mundial com 140 regiões, 57 setores e com o ano de referência de 2011. A seguir, são detalhadas as agregações consideradas a partir da base de dados do modelo GTAP.

\subsubsection{Agregação dos Setores e Fonte de Dados}

Neste trabalho, as regiões e os setores escolhidos foram agrupados (Quadro 1) em quatro regiões - Brasil, China, Estados Unidos e resto do mundo -, e em 10 setores. Entre esses setores, estão os de grãos, frutas e legumes, cana-de-açúcar e outros, pecuária e carnes, produtos agroindustriais. A escolha buscou dividir os setores do agronegócio nessas cinco categorias para captar melhor os impactos no agronegócio brasileiro. Os demais setores foram classificados como extração, aço 
(proxy), produtos de baixa e média-baixa tecnologia, produtos de média-alta e alta tecnologia e serviços.

Quadro 1 - Agregações regionais e setoriais

\begin{tabular}{|l|l|}
\hline Agregação regional & Agregação setorial \\
\hline Brasil & 1-Grãos: arroz em casca, trigo, grãos de cereais, sementes oleaginosas. \\
Estados Unidos & 2-Frutas e legumes: legumes, frutas, nozes. \\
Resto do mundo & $\begin{array}{l}\text { 3-Cana-de-açúcar e outros: cana-de-açúcar, beterraba, sacarina, fibras à base } \\
\text { de plantas e outras culturas. } \\
\text { 4-Pecuária e carnes: gado, ovelhas, cabras, cavalos, produtos animais, leite } \\
\text { cru, lã, casulos de bicho da seda; carne: gado bovino, ovino, caprino, cavalo, } \\
\text { produtos de carne e pescaria. }\end{array}$ \\
& $\begin{array}{l}\text { 5-Produtos agroindustriais: óleos e gorduras vegetais, lacticínios, açúcar, } \\
\text { produtos alimentares, bebidas e produtos de tabaco e arroz processado. }\end{array}$ \\
& $\begin{array}{l}\text { 6-Extração: silvicultura, carvão, óleo, gás. } \\
\text { 7-Aço (proxy): metais ferrosos. } \\
\text { 8-Produtos de baixa e média-baixa tecnologia: têxteis, roupas, produtos } \\
\text { de couro, produtos de madeira, produtos de papel, publicações, petróleo, } \\
\text { produtos de carvão, produtos minerais, outros minerais, produtos de metal e } \\
\text { outros metais. } \\
\text { 9-Produtos de média-alta e alta tecnologia: veículos a motor e peças, } \\
\text { equipamentos de transporte, fábrica, química, borracha, bastões de plástico, } \\
\text { equipamento eletrônico, máquinas e outros equipamentos. } \\
\text { 10-Serviços: eletricidade, fabricação de gás, distribuição, água, construção, } \\
\text { comércio, transporte, transporte marítimo, transporte aéreo, comunicação, } \\
\text { serviços, financeiros, seguro, serviços de negócios, recreação e outros } \\
\text { serviços, administração pública, defesa, saúde, educação, moradias. }\end{array}$ \\
\hline
\end{tabular}

Fonte: Elaboração própria a partir de dados do GTAP 9 (2018).

O equilíbrio inicial foi caracterizado pela economia, no ano de 2011, de acordo com a base de dados do GTAP na versão 9. Em geral, as informações macroeconômicas são provenientes do Banco Mundial, as de comércio de mercadorias vêm da base de dados Comtrade e a de serviços, das estatísticas de balanços de pagamentos do Fundo Monetário Internacional (SILVA, 2017).

Com agregação em nível regional, buscou-se observar o comércio do Brasil com os seus principais parceiros comerciais, China e Estados Unidos, que foram deixados como regiões/países isolados. A agregação setorial foi utilizada para identificar os impactos da atual disputa comercial entre China e Estados Unidos no agronegócio brasileiro, no curto prazo. 


\subsubsection{Elaboração dos Cenários}

Tendo em vista que o trabalho objetiva identificar os impactos parciais da atual disputa comercial entre China e Estados Unidos no agronegócio brasileiro, foram realizados dois cenários diferentes para estas simulações:

a) cenário um - disputa comercial entre China e Estados Unidos com proteção comercial parcial: aumento nas tarifas de importação de $25 \%$ sobre o aço exportado dos Estados Unidos para a China (seção 232 da Lei de Expansão do Comércio de 1962 e seção 301 da Lei de Comércio de 1974); ; a China toma medida retaliatória, impondo aumento nas tarifas de $25 \%$ sobre os produtos agrícolas (grãos, carnes e cana-de-açúcar) importados dos Estados Unidos pela China (retaliação sob seção 232 da Lei de Expansão do Comércio de 1962 e seção 301 da Lei de Comércio de 1974);

b) cenário dois (alternativo) - disputa comercial entre China e Estados Unidos com proteção comercial completa: os Estados Unidos impõem um aumento nas tarifas de importação de $25 \%$ sobre todas as mercadorias obtidas da China, e esta toma a medida retaliatória impondo $25 \%$ de aumento de tarifa sobre todas as mercadorias obtidas dos Estados Unidos.

Para a realização desses cenários, foram utilizados equivalentes tarifários comerciais, que são a média ponderada para calcular a tarifa adicional (TMS) no GTAP. No entanto, não há setor siderúrgico no GTAP, desse modo foram utilizados os produtos agregados no setor denominado aço, como uma proxy, produtos metais ferrosos (I_S), que melhor reflete o setor econômico de siderurgia no modelo.

\subsubsection{Elasticidades de Substituição}

Nas simulações dos cenários propostos pelo MEGC do GTAP, os resultados são influenciados pelos valores assumidos tanto pelas tarifas iniciais, que são removidas ou acrescentadas, quanto também pelas elasticidades de substituição (Tabela 1). Estas referem-se às elasticidades de substituição entre os fatores primários (ESUBVA), entre os bens domésticos e importados da estrutura de agregação de Armington (ESUBD) e entre importações de diferentes fontes (ESUBM).

2 Seção 301 da Lei de Comércio de 1974, o United States Trade Representative iniciou uma investigação para determinar se os atos, as políticas e as práticas da China relacionados à transferência de tecnologia, propriedade intelectual e inovação não são razoáveis ou são discriminatórios e oneram ou restringem o comércio dos Estados Unidos (UNITED STATES TRADE REPRESENTATIVE, 2018). A Seção 232 da Lei de Expansão do Comércio de 1962, como emendada, dá ao poder executivo a capacidade de conduzir investigações para determinar os efeitos sobre a segurança nacional das importações (UNITED STATES TRADE REPRESENTATIVE, 2018). 
Tabela 1 - Elasticidades de substituição

\begin{tabular}{lccc}
\hline SETORES & ESUBVA & ESUBD & ESUBM \\
\hline Grãos & 0,26 & 3,11 & 5,47 \\
Frutas e legumes & 0,26 & 1,85 & 3,70 \\
Cana-de-açúcar e outros & 0,26 & 3,04 & 6,18 \\
Pecuária e carnes & 0,46 & 2,90 & 6,82 \\
Extração & 0,20 & 6,37 & 13,58 \\
Produtos agroindustriais & 1,12 & 2,17 & 4,50 \\
Aço & 1,26 & 2,95 & 5,90 \\
Produtos de baixa e média-baixa tecnologia & 1,26 & 2,84 & 5,93 \\
Produtos de média-alta e alta tecnologia & 1,26 & 3,67 & 7,40 \\
Serviços & 1,36 & 1,94 & 3,85 \\
\hline
\end{tabular}

Fonte: Elaboração própria a partir do GTAP 9.

Assim, a "[...] direção e a magnitude dos efeitos de uma mudança da política comercial não dependem somente do tamanho do choque, mas também das elasticidades de cada setor, que refletem o tamanho do impacto que uma variação no preço exerce sobre a demanda [...]" (OLIVEIRA; AZEVEDO, 2018, p. 164). Então, um aumento nas tarifas de importações impactará diretamente nos setores de produção e de bens de uma economia conforme a magnitude das elasticidades, uma vez que, "[...] quanto mais próxima de 0 a elasticidade de substituição, menor a capacidade de se substituir um insumo por outro [...]" (COSTA, 2008, p. 113).

\subsubsection{Fechamento do Modelo}

O fechamento ou closure macroeconômico do GTAP utilizado nesse modelo é chamado de neoclássico, uma vez que a estrutura do modelo GTAP é de competição perfeita e retornos constantes de escala (OLIVEIRA; AZEVEDO, 2018). Nesse fechamento, é importante destacar que o investimento se ajuste a variações na poupança. Os fatores de produção que têm mobilidade entre os setores são capital e mão de obra. O grau de mobilidade dos fatores de produção é governado por uma elasticidade de transformação constante, e a terra é o fator de produção imóvel.

O fechamento desse modelo foi adotado para todas as simulações. Sob esse fechamento, os parâmetros de elasticidade de preço podem responder ao choque tanto do lado da oferta quanto do da demanda.

\section{Análise e Discussão dos Resultados}

Nesta seção, apresenta-se a análise dos resultados. Primeiramente, na subseção 4.1, discute-se a relação comercial entre Brasil, China e Estados Unidos. Em 
seguida, analisam-se os resultados obtidos das soluções dos cenários, simulados pelo MEGC-GTAP.

\subsection{Análise das Relações Comerciais entre Brasil, China e Estados Unidos}

Os Estados Unidos possuem um PIB de US $\$ 18,6$ trilhões e um PIB per capita de US $\$ 57,6$ mil, portanto considerado a segunda maior economia do mundo, sendo a primeira a China. Em 2016, os Estados Unidos exportaram aproximadamente US \$ 1,32 trilhões. Entretanto, suas importações foram de aproximadamente US\$ 2,12 trilhões, resultando em um saldo comercial negativo (déficit) de aproximadamente de US $\$ 800$ bilhões (OBSERVATORY OF ECONOMIC COMPLEXITY, 2018).

Destaca-se que, em 2017, os Estados Unidos importaram aproximadamente US $\$ 506$ bilhões em produtos chineses e exportaram mais de US $\$ 130$ bilhões para a China, o que resultou em um déficit comercial de US $\$ 375$ bilhões e, consequentemente, representou um aumento de $8,2 \%$ de déficit (US $\$ 28,6$ bilhões) em relação a 2016 (UNITED STATES CENSUS BUREAU, 2018).

Identifica-se que, ao longo dos anos, as importações dos Estados Unidos cresceram mais do que as suas exportações. Segundo Liu et al. (2018), nas relações comerciais entre China e Estados Unidos, enquanto as importações da China mantiveram-se concentradas em uma pauta de produtos do setor agrícola e manufatureiro, as importações dos Estados Unidos concentram-se em produtos de informática e eletrônicos, ou seja, de alta intensidade tecnológica. Então, com o objetivo de reduzir o déficit comercial, o governo dos Estados Unidos implementou uma série de tarifas sobre os produtos importados da China, o que levou a ações de retaliação por parte do governo chinês.

Convém destacar que, entre as exportações totais dos Estados Unidos para a China, os produtos agrícolas totalizaram US $\$ 20$ bilhões em 2017, tornando-se o segundo maior mercado de exportação agrícola dos Estados Unidos. Os principais produtos exportados são soja (US\$ 12 bilhões), algodão (US $\$ 978$ milhões), peles e couros (US\$ 945 milhões), grãos grandes e milho (US\$ 839 milhões) e carne suína (US\$ 662 milhões) (UNITED STATES DEPARTMENT OF AGRICULTURE, 2018).

As exportações de serviços dos Estados Unidos para a China foram aproximadamente de US $\$ 57,6$ bilhões em 2017, 4,9\% (US $\$ 2,7$ bilhões) a mais do que em 2016. As principais exportações de serviços concentraram-se nos setores de viagens, propriedade intelectual (marca registrada, software de computador) e transporte, enquanto os principais serviços exportados da China para os Estados Unidos concentraram-se nos setores de viagens, transporte e pesquisa e desenvolvimento (UNITED STATES TRADE REPRESENTATIVE, 2018).

Em suas relações comerciais, a China tem como principal destino de exportação de produtos os Estados Unidos. As principais categorias de produtos expor- 
tados da China para os Estados unidos são maquinaria elétrica (US $\$ 147$ bilhões), maquinaria (US $\$ 110$ bilhões), móveis e roupas de cama (US $\$ 32$ bilhões), brinquedos e equipamentos esportivos (US $\$ 26$ bilhões) e plásticos (US $\$ 16$ bilhões). Ainda, a China negocia, em suas exportações com os Estados Unidos, produtos agrícolas, que totalizaram US $\$ 4,5$ bilhões em 2017, sendo como principais mercadorias frutas e vegetais processados (US $\$ 1,1$ bilhão), sucos de frutas e vegetais (US\$ 320 milhões), salgadinhos (US\$204 milhões), vegetais frescos (US\$181 milhões) e especiarias (US\$ 159 milhões) (UNITED STATES TRADE REPRESENTATIVE, 2018).

Como enfatizado, a China e os Estados Unidos são as duas maiores economias do mundo, que representam cerca de um terço do valor da economia mundial total, bem como também os destinos da maioria dos investimentos estrangeiros diretos. Destaca-se que o investimento estrangeiro direto dos Estados Unidos na China foi de US $\$ 107,6$ bilhões em 2017, um aumento de 10,6\% em relação a 2016, liderado pelos setores de manufatura, comércio atacadista e finanças e seguros. Já o investimento estrangeiro direto da China nos Estados Unidos foi de US\$ 39,5 bilhões em 2017, uma queda de 2,3\% em relação a 2016, liderado pelos setores de instituições manufatureiras, imobiliárias e depositárias (UNITED STATES TRADE REPRESENTATIVE, 2018).

As relações comerciais entre a China e os Estados Unidos impactam de maneira direta ou indireta nos demais países, por isso uma disputa comercial (guerra comercial) entre as maiores potências do mundo pode impactar significamente o Brasil, o qual tem ambos os países como principais parceiros comerciais, além de ser respectivamente o primeiro e segundo destinos de suas exportações.

O Brasil é a vigéssima quarta maior economia de exportação no mundo (OBSERVATORY OF ECONOMIC COMPLEXITY, 2018). Em 2017, o Brasil exportou cerca de US $\$ 217,7$ bilhões e importou US $\$ 150,7$ bilhões, resultando em um saldo comercial positivo de US $\$ 66,9$ bilhões (MINISTÉRIO DO DESENVOLVIMENTO, INDÚSTRIA E COMÉRCIO EXTERIOR, 2018). Em 2016, o PIB foi de US\$ 1,8 trilhões e seu PIB per capita foi de US \$ 15,1 mil (OBSERVATORY OF ECONOMIC COMPLEXITY, 2018). Convém destacar que só o setor do agronegócio é responsável por aproximadamente $44 \%$ (U\$ $\$ 96$ bilhões) do total exportado do Brasil (U\$ $\$$ 217,7 bilhões), e a China, nesse setor, é o maior parceiro, pois aproximadamente $26 \%$ (US\$ 26,5 bilhões) do total dos produtos do agronegócio são destinados a exportações para esse mercado.

Ao analisar a participação da China e dos Estados Unidos no total das exportações do Brasil (Gráfico 1), observa-se que, a partir de 2007, as exportações para os Estados Unidos apresentaram queda em relação à China, a qual tornou-se um importante parceiro comercial do Brasil, apontando um aumento significativo no total da participação das exportações do Brasil. Destaca-se que a participação da 
China, em 2007, era cerca de 7\%. Já em 2017, essa participação passou a ser de $22 \%$, um aumento significativo de 15 pontos percentuais (MINISTÉRIO DO DESENVOLVIMENTO, INDÚSTRIA E COMÉRCIO EXTERIOR, 2018).

Gráfico 1 - Participação da China e dos Estados Unidos no total das exportações do Brasil (2007-2017)

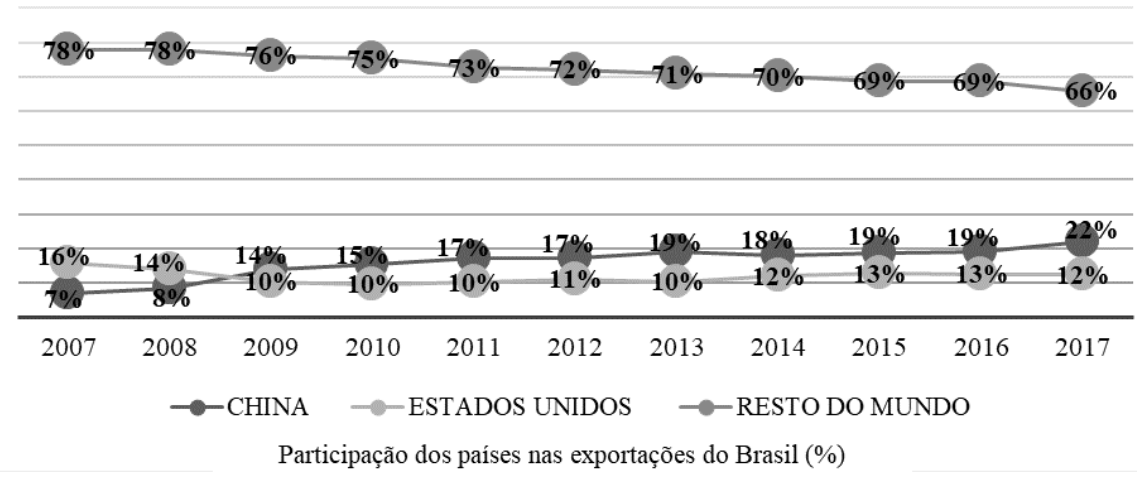

Fonte: Elaboração própria a partir de dados do Ministério do Desenvolvimento, Indústria e Comércio Exterior (2018).

Os principais produtos exportados do Brasil para a China (Tabela 2), classificados em um ranking, são produtos do setor primário, respectivamente soja (mesmo triturada, exceto para semeadura), minérios de ferro e óleos brutos de petróleo. Assim, verifica-se a importância do setor do agronegócio, no qual a soja lidera as exportações do Brasil para a China, com participação de 42,77\% (US\$20.310,2 milhões) em 2017. Essa evolução foi significativa, já que, no ano de 2010, a participação da soja era de $23,20 \%$ (US\$ 7.133,4 milhões). Além da soja, destacam-se as carnes de frango, bovinos e fumo, estando entre os 10 principais produtos exportados, como mostra o ranking.

Tabela 2 - Principais produtos exportados do Brasil para a China (2010 e 2017)

\begin{tabular}{lccccccc}
\hline \multirow{2}{*}{ Produtos } & \multicolumn{2}{c}{$\begin{array}{c}\text { Exportações } \\
\text { (FOB US\$ } \\
\text { milhóes) }\end{array}$} & & \multicolumn{2}{c}{ Ranking } & \multicolumn{2}{c}{$\begin{array}{c}\text { Participação } \\
\text { (\%) }\end{array}$} \\
\cline { 2 - 8 } & 2010 & 2017 & 2010 & 2017 & 2010 & 2017 \\
\hline Soja, mesmo triturada, exceto para semeadura & $7.133,4$ & $20.310,2$ & $2^{\circ}$ & $1^{\circ}$ & 23,20 & 42,77 \\
\hline $\begin{array}{l}\text { Minérios de ferro e seus concentrados, exceto } \\
\text { as piritas de ferro ustuladas (cinzas de piritas), } \\
\text { não aglomerados }\end{array}$ & $12.178,9$ & $10.240,1$ & $1^{\circ}$ & $2^{\circ}$ & 39,61 & 21,56 \\
\hline Óleos brutos de petróleo & 4,0 & $7.351,1$ & $3^{\circ}$ & $3^{\circ}$ & 13,18 & 15,48 \\
\hline
\end{tabular}

Continua... 


\begin{tabular}{|c|c|c|c|c|c|c|}
\hline \multirow[t]{2}{*}{ Produtos } & \multicolumn{2}{|c|}{$\begin{array}{c}\text { Exportações } \\
\text { (FOB US\$ } \\
\text { milhões) }\end{array}$} & \multicolumn{2}{|c|}{ Ranking } & \multicolumn{2}{|c|}{$\begin{array}{c}\text { Participação } \\
\text { (\%) }\end{array}$} \\
\hline & 2010 & 2017 & 2010 & 2017 & 2010 & 2017 \\
\hline $\begin{array}{l}\text { Pastas químicas de madeira, à soda ou } \\
\text { ao sulfato, exceto pastas para dissolução, } \\
\text { semibranqueadas ou branqueadas, de não } \\
\text { coníferas }\end{array}$ & 908,9 & $2.099,5$ & $5^{\circ}$ & $4^{\circ}$ & 2,96 & 4,42 \\
\hline Carnes desossadas de bovino congeladas & 4,9 & 928,8 & $92^{\circ}$ & $5^{\circ}$ & 0,02 & 1,96 \\
\hline $\begin{array}{l}\text { Pedaços e miudezas, comestíveis de galos/ } \\
\text { galinhas, congelados }\end{array}$ & 219,5 & 760,5 & $11^{\circ}$ & $6^{\circ}$ & 0,71 & 1,60 \\
\hline Ferro-nióbio & 325,4 & 426,8 & $10^{\circ}$ & $7^{\circ}$ & 1,06 & 0,90 \\
\hline Pasta química de madeira para dissolução & 216,9 & 420,7 & $12^{\circ}$ & $8^{\circ}$ & 0,71 & 0,89 \\
\hline $\begin{array}{l}\text { Outros aviões e outros veículos aéreos, de peso } \\
\text { superior a } 15.000 \mathrm{~kg} \text {, vazios }\end{array}$ & 368,4 & 395,7 & $8^{\circ}$ & $9^{\circ}$ & 1,20 & 0,83 \\
\hline $\begin{array}{l}\text { Tabaco não manufaturado, total ou } \\
\text { parcialmente destalado, em folhas secas em } \\
\text { secador de ar quente (flue cured) do tipo } \\
\text { Virgínia }\end{array}$ & 343,1 & 273,3 & $9^{\circ}$ & $10^{\circ}$ & 1,12 & 0,58 \\
\hline Outros & 4.994, 3 & $4.281,3$ & - & - & 16,24 & 9,02 \\
\hline Total & $30.747,5$ & $47.488,4$ & - & - & 100 & 100 \\
\hline
\end{tabular}

Fonte: Elaboração própria a partir de dados de Comexstat e Ministério do Desenvolvimento, Indústria e Comércio Exterior (2018).

Quanto aos principais produtos que o Brasil importou da China (Tabela 2) em 2017, destacam-se, por fator agregado, produtos manufaturados (U $\$ 3,28$ bilhões), serviços diversos de telefonia (US $\$ 1,41$ bilhões), partes de aparelhos transmissores ou receptores (US\$1,17 bilhões), compostos heterocíclicos, seus sais e sulfonamidas (US\$850,51 milhões) e circuitos integrados e microconjuntos eletrônicos (US\$ 780,04 milhões). O total importado da China, nesse período, foi US\$ 27,32 bilhões. Identifica-se que, nas importações do Brasil em relação à China, a pauta é caracterizada por produtos de média e alta intensidade tecnológica, enquanto a pauta importadora da China em relação ao Brasil concentra-se em produtos primários, em especial do setor do agronegócio, como já mencionado.

Em relação ao comércio entre Brasil e Estados Unidos (Tabela 3), percebe-se que o principal produto exportado, ao longo dos anos, foram os óleos brutos de petróleo, com uma participação de 19,95\% (US\$2.648,4 milhões) em 2017, que se manteve na primeira posição do ranking, no período analisado. Destaca-se, ainda, a evolução dos produtos na categoria de outros aviões e outros veículos aéreos, de peso superior a $15.000 \mathrm{~kg}$, vazios, considerado de alta intensidade tecnologia, que, no ano de 2010 , ocupava a posição de $14^{\circ}$ (US $\$ 188,6$ milhões) no ranking dos produtos exportados, passando a ocupar, em 2017, a posição de terceiro, com uma participação na pauta exportadora de 7\% (US\$1.880,0 milhões). 
Tabela 3 - Principais produtos exportados do Brasil para os Estados Unidos (2010 e 2017)

\begin{tabular}{|c|c|c|c|c|c|c|}
\hline \multirow[t]{2}{*}{ Produtos } & \multicolumn{2}{|c|}{$\begin{array}{l}\text { Exportações (FOB } \\
\text { US\$ milhões) }\end{array}$} & \multicolumn{2}{|c|}{ Ranking } & \multicolumn{2}{|c|}{ Participação (\%) } \\
\hline & 2010 & 2017 & 2010 & 2017 & 2010 & 2017 \\
\hline Óleos brutos de petróleo & $3.849,5$ & $2.648,4$ & $1^{\mathrm{o}}$ & $1^{\mathrm{o}}$ & 19.95 & 9.86 \\
\hline $\begin{array}{l}\text { Partes de turborreatores ou de } \\
\text { turbopropulsores }\end{array}$ & 8,7 & $2.172,1$ & $241^{\circ}$ & $2^{\circ}$ & 0.05 & 8.08 \\
\hline $\begin{array}{l}\text { Outros aviões e outros veículos aéreos, de } \\
\text { peso superior a } 15.000 \mathrm{~kg} \text {, vazios }\end{array}$ & 188,6 & $1.880,0$ & $14^{\circ}$ & $3^{\circ}$ & 0.98 & 7.00 \\
\hline $\begin{array}{l}\text { Outros produtos semimanufaturados } \\
\text { de ferro ou aço não ligado, de seção } \\
\text { transversal retangular, que contenham, em } \\
\text { peso, menos de } 0,25 \% \text { de carbono. }\end{array}$ & 323,0 & $1.052,3$ & $6^{\circ}$ & $4^{\circ}$ & 1.67 & 3.92 \\
\hline $\begin{array}{l}\text { Pastas químicas de madeira, à soda ou } \\
\text { ao sulfato, exceto pastas para dissolução, } \\
\text { semibranqueadas ou branqueadas, de não } \\
\text { coníferas }\end{array}$ & 821,1 & 979,3 & $3^{\circ}$ & $5^{\circ}$ & 4.25 & 3.64 \\
\hline $\begin{array}{l}\text { Café não torrado, não descafeinado, em } \\
\text { grão }\end{array}$ & $1.061,4$ & 916,9 & $2^{\mathrm{O}}$ & $6^{\circ}$ & 5.50 & 3.41 \\
\hline $\begin{array}{l}\text { Produtos semimanufaturados, de outras } \\
\text { ligas de aços }\end{array}$ & 55,0 & 753,3 & $64^{\circ}$ & $7^{\circ}$ & 0.29 & 2.80 \\
\hline $\begin{array}{l}\text { Álcool etílico não desnaturado, com um } \\
\text { teor alcoólico, em volume, igual ou superior } \\
\text { a } 80 \text { \% do volume, com um teor de água } \\
\text { igual ou inferior a } 1 \% \text { do volume }\end{array}$ & 185,9 & 567,0 & 16 & $8^{\circ}$ & 0.96 & 2.11 \\
\hline $\begin{array}{l}\text { Outros granitos trabalhados de outro modo } \\
\text { e suas obras }\end{array}$ & 459,7 & 494,0 & $5^{\circ}$ & $9^{\circ}$ & 2.38 & 1.84 \\
\hline $\begin{array}{l}\text { Ouro em barras, fios e perfis de seção } \\
\text { maciça }\end{array}$ & 200,5 & 403,5 & $11^{\circ}$ & $10^{\circ}$ & 1.04 & 1.50 \\
\hline Outros & $12.146,8$ & $15.005,7$ & - & - & 62.93 & 55.84 \\
\hline Total & $19.300,9$ & $26.872,6$ & - & - & 100.00 & 100 \\
\hline
\end{tabular}

Fonte: Elaboração própria a partir de dados de Comexstat e Ministério do Desenvolvimento, Indústria e Comércio Exterior (2018).

Quanto aos principais produtos que o Brasil importou dos Estados Unidos em 2017, destacam-se, por fator agregado, óleos combustíveis (US $\$ 4,47$ bilhões), medicamentos para medicina humana e veterinária (US $\$ 1,1$ bilhões), hulha, mesmo em pó, mas não aglomerada (US\$ 1,07 bilhões), demais produtos manufaturados (US\$ 987,9 milhões), etanol (US\$ 898,27 milhões), gasolina (US \$ 711,32 milhões), partes de motores e turbinas para aviação (681,81 milhões) e adubos ou fertilizantes (673,29 milhões). O total importado dos Estados Unidos nesse período foi US\$ 24,85 bilhões (MINISTÉRIO DO DESENVOLVIMENTO, INDÚSTRIA E COMÉRCIO EXTERIOR, 2018). Identifica-se que as importações brasileiras são caracterizadas por uma diversificação de produtos, no entanto concentram-se no setor de 
transporte e da indústria. Ainda do total exportado para os Estados Unidos, 7\% é direcionado à reexportação (MINISTÉRIO DO DESENVOLVIMENTO, INDÚSTRIA E COMÉRCIO EXTERIOR, 2018).

\subsection{Análise dos Impactos da Disputa Comercial entre Estados Unidos e China sobre o Agronegócio Brasileiro a partir das Simulações dos Cenários Propostos}

A seguir, apresentam-se os resultados dos cenários da disputa comercial entre China e Estados Unidos, com os quais se buscou verificar os impactos para a economia, bem como para o agronegócio brasileiro. Os cenários dividem-se em: cenário um, disputa comercial entre China e Estados Unidos com proteção comercial parcial; e cenário dois, disputa comercial entre China e Estados Unidos com proteção comercial completa.

Para atender aos objetivos do estudo, esta seção divide-se em três subseções: na primeira, contemplam-se os impactos no bem-estar e na economia global; na segunda subseção, expõem-se os impactos no agronegócio brasileiro; e, na terceira subseção, apresenta-se a análise de sensibilidade.

\subsubsection{Impactos no Bem-Estar e na Economia Global}

A Tabela 4 mostra os resultados dos indicadores de bem-estar estar (EV), bem como de seus componentes (efeito alocativo, termos de troca e investimento-poupança $)^{3}$ e o crescimento da economia para os cenários propostos. Ao se analisar os resultados da simulação dos cenários, evidencia-se que o impacto da disputa comercial entre os Estados Unidos e a China são negativos para ambas as economias.

3 Os termos de troca são a razão entre os preços internacionais e os preços domésticos, a eficiência alocativa é a alocação de recursos de forma que sejam distribuídos da melhor forma possível (CARVALHO; AZEVEDO; MASSUQUETTI, 2019), os efeitos de investimento e poupança dependem do preço da economia e do investimento e se a região é um fornecedor líquido ou um receptor líquido de economia, ou seja, variação de cada região (HUFF; HERTEL, 2000), em que as regiões fornecedoras líquidas de poupança para o banco global se beneficiam de um aumento no preço da economia em relação aos bens de investimento, enquanto os receptores líquidos perdem (CARVALHO; AZEVEDO; MASSUQUETTI, 2019). 
Tabela 4 - Efeitos sobre o bem-estar e seus componentes (milhões de US\$) no PIB $(\Delta \%)$

\begin{tabular}{lccccc}
\hline \multirow{2}{*}{ Região } & $\begin{array}{c}\text { Efeito } \\
\text { alocativo }\end{array}$ & $\begin{array}{c}\text { Efeito } \\
\text { termos de } \\
\text { troca }\end{array}$ & Efeito I-S & $\begin{array}{c}\text { Efeito total } \\
\text { bem-estar } \\
\text { (EV) }\end{array}$ & PIB $\boldsymbol{\Delta} \%$ \\
\cline { 2 - 6 } & \multicolumn{5}{c}{ Cenário um } \\
\hline China & $-2584,62$ & 304,21 & 241,71 & $-2038,70$ & 0,02 \\
\hline Estados Unidos & 154,56 & $-2782,29$ & $-545,51$ & $-3173,24$ & $-0,10$ \\
\hline Brasil & 107,08 & 726,94 & $-2,42$ & 831,60 & 0,27 \\
\hline Resto do mundo & 844,9 & 1749 & 305,93 & 2899,83 & 0,02 \\
\hline Total & $-1478,07$ & $-2,13$ & $-0,28$ & $-1480,48$ & 0,21 \\
\hline \multicolumn{5}{c}{ Cenário dois } \\
\hline China & $-33135,73$ & $-43172,48$ & 4993,87 & $-71314,33$ & $-2,95$ \\
\hline Estados Unidos & $-34769,18$ & $-5824,76$ & $-285,26$ & $-40879,19$ & $-0,35$ \\
\hline Brasil & 958,69 & 1713,35 & $-107,88$ & 2564,17 & 0,90 \\
\hline Resto do mundo & 12712,87 & 46701,27 & $-4535,57$ & 54878,58 & 0,67 \\
\hline Total & $-54233,34$ & $-582,61$ & 65,16 & $-54750,79$ & $-1,73$ \\
\hline
\end{tabular}

Fonte: Elaboração própria a partir do GTAP 9.

Na primeira simulação, observa-se uma queda no PIB dos Estados Unidos de $-0,10 \%$, enquanto os efeitos no PIB para a China, Brasil e o resto do mundo são relativamente pequenos, cerca de $0,02,0,27 \%$ e $0,02 \%$, respectivamente, e positivos. Isso indica que essas medidas de tarifas inicialmente impostas pelos Estados Unidos não gerarão os efeitos esperados, como a retomada de sua indústria, geração de empregos e crescimento da economia (INSTITUTO DE ESTUDO PARA O DESENVOLVIMENTO INDUSTRIAL, 2019). Na segunda simulação, evidenciam-se efeitos negativos para os Estados Unidos e para a China, com uma queda no PIB de -0,35 e $-2,95 \%$, respectivamente. Para o Brasil e o resto do mundo, evidenciam-se efeitos relativamente pequenos no PIB para economia global.

Nos cenários simulados, identifica-se que a introdução de medidas protecionistas (tarifas ad valorem) intensificará os efeitos negativos para China e Estados Unidos, pois todas essas medidas são susceptíveis de ser contrabalançadas por ações de políticas adicionais retaliatórias. Assim, ao comparar os efeitos sob a disputa comercial mútua, a China perderá mais que os Estados Unidos, como observado na simulação do segundo cenário, uma vez que o impacto negativo sobre o PIB da China é maior do que o dos Estados Unidos. Destacam-se os trabalhos de Li-Chunding, He-Chuantian e Lin-Chuangwei (2018) e Rosyadi e Widodo (2017), os quais corroboram esses resultados.

Para a análise dos efeitos do bem-estar, considera-se que haverá melhoria de bem-estar se a variação equivalente (EV) for positiva, e o contrário implica perda de bem-estar (OLIVEIRA; MATA; TEIXEIRA, 1999). O primeiro cenário simulado mostra que tanto a China quanto os Estados Unidos diminuem seu bem-estar, res- 
pectivamente, com uma perda de US\$ $-2038,70$ milhões e US\$ $-3173,24$ milhões. No segundo cenário, a perda de bem-estar para a China e os Estados Unidos é maior do que foi apontado no primeiro cenário, apresentando, respectivamente, uma perda de US $\$-71314,33$ e US $\$-40879,19$. Esses resultados demonstram que medidas de restrições (protecionismo) comercial entre dois países podem levar a grandes mudanças no efeito de bem-estar dos países, dado que a ação de um país em proteger sua economia com uma tarifa de importação é sempre suscetível de ser respondida por retaliação de seu parceiro (país) comercial (ROSYADI; WIDODO, 2017). Quanto ao Brasil e o resto do mundo, em ambos os cenários apresentam-se efeitos de ganhos de bem-estar em suas economias com a disputa comercial entre a China e o Estados Unidos.

Os resultados obtidos estão em consonância com os estudos de Gonçalves et al. (2018), que, ao realizarem as simulações dos aumentos de tarifas de importação de $25 \%$ sobre os produtos exportados dos Estados Unidos para a China e sobre as medidas retaliatórias da China, impondo aumento nas tarifas similares de $25 \%$ nos produtos exportados dos Estados Unidos (seção 232 da Lei de Expansão do Comércio de 1962 e seção 301 da Lei de Comércio de 1974), apontaram que os mais prejudicados nessa disputa comercial, tanto em termos de bem-estar ou de termos de troca, são eles próprios, China e Estados Unidos, obtendo efeitos negativos em suas economias. Ou seja, os efeitos no bem-estar são negativos tanto para os Estados Unidos quanto para a China. Assim, com essas simulações, as disputas comerciais estariam afetando negativamente o bem-estar global, com a China perdendo

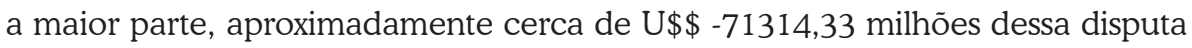
com os Estados Unidos (US\$-40879,19), como observado no segundo cenário.

Gonçalves et al. (2018) evidenciam, ainda, que o Brasil e a União Europeia, em relação aos termos de trocas, são os países que apresentam a maior melhoria em detrimento das demais regiões com a disputa comercial entre a China e os Estados Unidos, corroborando este estudo, que evidenciou melhora nos termos de troca para o Brasil nos dois cenários simulados (U\$ \$ 726,94 milhões e U\$ \$ 1713,35 milhões) e para o resto do mundo (U\$ \$ 1749,0 milhões e U\$ \$ 46701,27 milhões).

Quanto aos efeitos alocativos (Tabela 4), são os principais responsáveis pelo aumento ou diminuição do bem-estar. Nota-se que, no primeiro cenário, a China é o país mais prejudicado, chegando a US $\$-2584,62$ milhões, causado pela perda em eficiência alocativa nos setores de produtos agropecuários, média-alta e alta tecnologia e serviço. Já os Estados Unidos obtiveram um efeito positivo (US\$ 154,56 milhões), contudo apresentaram perda em eficiência alocativa nos setores de aço e baixa e baixa-média intensidade tecnológica, sendo o setor de aço o maior prejudicado, isto em decorrência do aumento em suas tarifas, impostas pelo próprio país (CARVALHO; AZEVEDO; MASSUQUETTI, 2019). 
No segundo cenário, observa-se que, ao se intensificar os conflitos comerciais (retaliações) entre a China e os Estados Unidos, ambos acabam apresentando perdas em eficiência alocativa, cerca de US $\$-33135,73$ milhões e US $\$-34769,18$ milhões, respectivamente, em razão da piora dos seus termos de troca (US\$ $-43172,48$ milhões e US \$ -5824,76 milhões, respectivamente). Em relação ao Brasil e ao resto do mundo, observa-se ganhos de eficiência alocativa, tanto no primeiro cenário (US\$ 107,08 milhões e US\$ 844,90 milhões, respectivamente), quanto no segundo cenário (US\$ 958,69 milhões e US $\$ 12712,87$ milhões, respectivamente) em razão da melhora em seus termos de trocas, como já ressaltado, refletindo-se diretamente em seus ganhos apresentados no bem-estar. Para o Brasil, esses ganhos de eficiência alocativa concentraram-se nos setores de média-alta e alta tecnologia, serviços, cana-de-açúcar e produtos agroindustriais.

Esses efeitos são gerados pelo aumento dos preços negociados entre China e Estados Unidos, em contrapartida de uma redução dos preços de importações das demais regiões que estão fora dessa disputa comercial, reduzindo seus preços para continuarem competitivas no mercado internacional, visto que uma consequência direta dessa disputa comercial entre China e Estados Unidos é a substituição de parte do comércio bilateral por produtos oriundos de terceiros países (UNITED NATIONS CONFERENCE ON TRADE AND DEVELOPMENT, 2019).

Estimativas apresentadas pela United Nations Conference On Trade And Development (2019) quanto aos possíveis efeitos da disputa comercial entre a China e os Estados Unidos sobre os países em desenvolvimento destacam que a União Europeia aparece como a maior beneficiada (primeira), porque as suas exportações são as que mais vão aumentar, capturando cerca de US $\$ 70$ bilhões do comércio bilateral Estados Unidos-China (US $\$ 50$ bilhões das exportações chinesas para os Estados Unidos e US $\$ 20$ bilhões de exportações dos Estados Unidos para a China), seguido por México (segundo), Japão (terceiro) e Canadá (quarto), os quais irão capturar acima de US $\$ 20$ bilhões. O Brasil aparece como o oitavo país com maior potencial de ganho, estimando-se que as exportações brasileiras poderão capturar cerca de US $\$ 10,5$ bilhões, o que representaria um aumento de 3,8\% em relação ao valor total exportado em 2017 (INSTITUTO DE ESTUDO PARA O DESENVOLVIMENTO INDUSTRIAL, 2019).

\subsubsection{Impactos no Agronegócio Brasileiro: Cenários um e dois}

Para verificar o impacto no agronegócio brasileiro causado pelo aumento das tarifas mútuas entre a China e Estados Unidos, em sua atual disputa comercial, buscou-se analisar, em termos de mudanças (variações percentuais $\Delta \%$ ), as exportações, importações, quantidade produzida e preços domésticos dos setores (Tabela 5). 
Tabela 5 - Mudanças nas exportações, importações, quantidade produzida e preços domésticos brasileiros nos cenários um e dois: em variações percentuais $(\Delta \%)$

\begin{tabular}{|c|c|c|c|c|}
\hline \multirow[b]{2}{*}{ Setores } & \multicolumn{4}{|c|}{ Cenário um } \\
\hline & $\begin{array}{c}\text { Valores das } \\
\text { exportações } \\
\text { (vxwfob) }\end{array}$ & $\begin{array}{l}\text { Valores das } \\
\text { importações } \\
\text { (viwcif) }\end{array}$ & $\begin{array}{c}\text { Quantidades } \\
\text { produzidas } \\
(q 0)\end{array}$ & $\begin{array}{l}\text { Preços } \\
\text { domésti- } \\
\text { cos }(p m)\end{array}$ \\
\hline & \multicolumn{4}{|c|}{$\Delta \%$} \\
\hline Grãos & 9,86 & 2,09 & 3,46 & 0,76 \\
\hline Frutas e legumes & $-1,20$ & 0,40 & $-0,54$ & 0,41 \\
\hline Cana-de-açúcar e outros & $-1,17$ & 2,62 & $-0,42$ & 0,42 \\
\hline Pecuária e carnes & $-1,63$ & 0,95 & $-0,31$ & 0,37 \\
\hline Extração & 0,20 & $-0,31$ & $-0,15$ & $-0,01$ \\
\hline Produtos agroindustriais & $-0,70$ & 0,63 & $-0,19$ & 0,33 \\
\hline Aço & 0,31 & 0,36 & $-0,18$ & 0,21 \\
\hline Produtos de baixa e média-baixa tecnologia & $-0,71$ & 0,31 & $-0,26$ & 0,18 \\
\hline Produtos de média-alta e alta tecnologia & $-1,13$ & 0,55 & $-0,21$ & 0,20 \\
\hline Serviços & $-0,61$ & 0,44 & 0,01 & 0,24 \\
\hline \multicolumn{5}{|c|}{ Cenário dois } \\
\hline \multirow[t]{2}{*}{ Setores } & $\begin{array}{c}\text { Valores das } \\
\text { exportações } \\
(v x w f o b)\end{array}$ & $\begin{array}{l}\text { Valores das } \\
\text { importações } \\
\text { (viwcif) }\end{array}$ & $\begin{array}{l}\text { Quantidades } \\
\text { produzidas (qo) }\end{array}$ & $\begin{array}{c}\text { Preços } \\
\text { domésticos } \\
(p m)\end{array}$ \\
\hline & \multicolumn{4}{|c|}{$\Delta \%$} \\
\hline Grãos & 6,40 & 2,08 & 1,92 & 1,06 \\
\hline Frutas e legumes & $-0,90$ & 0,80 & $-0,68$ & 0,83 \\
\hline Cana-de-açúcar e outros & $-1,21$ & 3,36 & $-0,54$ & 0,85 \\
\hline Pecuária e carnes & $-1,90$ & 1,83 & $-0,31$ & 0,86 \\
\hline Extração & 1,04 & $-0,36$ & $-0,28$ & 0,35 \\
\hline Produtos agroindustriais & $-0,75$ & 1,41 & $-0,25$ & 0,85 \\
\hline Aço & $-0,48$ & 1,50 & $-0,67$ & 0,73 \\
\hline Produtos de baixa e média-baixa tecnologia & $-1,05$ & 1,24 & $-0,59$ & 0,70 \\
\hline Produtos de média-alta e alta tecnologia & $-0,44$ & 2,01 & $-0,40$ & 0,70 \\
\hline Serviços & $-0,68$ & 1,26 & 0,11 & 0,85 \\
\hline
\end{tabular}

Fonte: Elaboração própria a partir do GTAP 9.

Diante dos resultados observados na Tabela 5, a partir da simulação do primeiro cenário - disputa comercial entre China e Estados Unidos com proteção comercial parcial -, a economia é submetida a um choque econômico de um aumento nas tarifas de importação de $25 \%$ sobre o aço exportado dos Estados Unidos para a China (seção 232 da Lei de Expansão do Comércio de 1962 e seção 301 da Lei de Comércio de 1974), e a China toma a medida retaliatória impondo aumento nas tarifas de $25 \%$ sobre os produtos agrícolas (grãos, carnes e cana-de-açúcar) importados dos Estados Unidos pela China (retaliação sob a seção 232 da Lei de Expansão do Comércio de 1962 e seção 301 da Lei de Comércio de 1974). Assim, 
é possível verificar que os impactos econômicos para os valores das exportações (vxwfob) do agronegócio brasileiro foram positivos apenas para o setor de grãos $(9,86 \Delta \%$ ), impulsionando um aumento na sua produção (qo) de 3,46 $\Delta \%$, evidenciando que esse setor obtém ganhos de eficiência econômica.

Nessas restrições comerciais entre os Estados Unidos e a China, o Brasil obtém ganhos no aumento de exportações dessas commodities causados pelo declínio acentuado que ocorre no comércio bilateral entre China e Estados Unidos e um aumento por importações para os seus terceiros parceiros comerciais, como, nesse caso, o Brasil, exportando mais grãos para a China. Nesse sentido, a United Nations Conference on Trade and Development (2019) destaca que, como a China responde por mais da metade das importações globais de soja em grãos do mundo, uma das principais consequências dessa disputa comercial é a alteração de parceiros comerciais da China, que irá favorecer vários países exportadores, especialmente o Brasil, que se tornará o principal fornecedor de soja em grãos para a China, e não mais os Estados Unidos, como era antes dessa disputa comercial.

Esse resultado justifica-se pelo fato de o Brasil e os Estados Unidos serem os principais exportadores de soja em grão para a China, e, nessa disputa comercial entre as maiores economias do mundo, a soja brasileira seria uma substituta natural do produto americano. Ademais, no ano de 2016, do total de exportações mundiais da soja, os Estados Unidos foram o maior exportador, respondendo por US\$ 22,8 bilhões, seguido pelo Brasil, com US $\$ 19,4$ bilhões e a Argentina, com US \$3,3 bilhões. Nesse mesmo período, a China importou aproximadamente 93,5 milhões de toneladas de soja, totalizando $65 \%$ das importações globais de soja, provenientes dos Estados Unidos (42\%), Brasil (44\%) e Argentina (9\%) (OBSERVATORY OF ECONOMIC COMPLEXITY, 2018).

O estudo de Taheripour e Tyner (2018) ${ }^{4}$ complementa essa análise, pois, em um de seus cenários simulados propostos, os autores avaliam o impacto da medida retaliatória da China ao impor um aumento de tarifa de $25 \%$ sobre as commodities agrícolas exportadas dos Estados Unidos, os quais evidenciaram que a produção de soja dos Estados Unidos tem uma redução (queda) de $11 \%$ a 15\%, enquanto essa produção no Brasil aumenta de $9 \%$ a $15 \%$.

Ao se aprofundar a análise nesse primeiro cenário, é possível identificar que, exceto no setor de grãos, a disputa comercial entre China e Estados Unidos causa impactos econômicos negativos, prejudicando a produção brasileira do agronegócio nos setores de frutas e legumes $(-1,20 \Delta \%)$, cana-de-açúcar e outros $(-1,17 \Delta \%)$, pecuária e carnes $(-1,63 \Delta \%)$ e produtos agroindustriais $(-0,70 \Delta \%)$, evidenciando que a produção passou a ser menos rentável.

$4 \quad$ A base de dados utilizada por Taheripour e Tyner (2018) é do GTAP versão 9, atualizada, respondendo aos dados da economia mundial de 2016. 
Quanto ao segundo cenário, identifica-se que a disputa comercial entre China e Estados Unidos com proteção comercial completa, na qual os Estados Unidos impõem 25\% de importação tarifária sobre todas as mercadorias obtidas da China, e a China toma medida retaliatória, impondo $25 \%$ de aumento de tarifa sobre todas as mercadorias obtidas dos Estados Unidos, grande parte dos setores da economia brasileira sofrem um impacto negativo nos valores das exportações (vxwfob) e na quantidade produzida (qo), em especial os setores do agronegócio, pecuária e carnes $(-1,90 \Delta \%)$, cana-de-açúcar e outros $(-1,22 \Delta \%)$, frutas e legumes $(-0,90 \Delta \%)$ e produtos agroindustriais $(-0,75 \Delta \%)$, nos quais se evidencia também que a produção passou a ser menos rentável.

Os cenários das simulações evidenciam efeitos positivos para o setor de grãos, especialmente a soja e o milho. Esse fato, consequentemente, eleva o aumento aos prêmios e preços dessas commodity, provocados pela disputa comercial entre China e Estados Unidos, aumentando a demanda dos setores de grãos brasileiros pelos compradores chineses, dificultando a competitividade e gerando um aumento nos custos dos demais setores e elos das cadeias do agronegócio, como, por exemplo, o setor de pecuária e carnes, produtos agroindustriais e produtos para a alimentação de animais, os quais são produzidos, fabricados e derivados da soja e do milho (UNITED NATIONS CONFERENCE ON TRADE AND DEVELOPMENT, 2019).

Dessa forma, com exceção do setor de grãos, o setor do agronegócio brasileiro é prejudicado com essa disputa comercial entre China e Estados Unidos, com efeitos negativos nos setores da pecuária e carnes, nos quais o país possui vantagem competitiva. Esse efeito negativo vem do deslocamento dos fatores produtivos (terra, capital e trabalho) dos vários setores agropecuários em direção ao setor de grãos, que é o principal setor de exportação do Brasil para a China e compete diretamente com os Estados Unidos nesse mercado, causando efeitos de queda na produção dos demais setores agregados do agronegócio.

$\mathrm{Na}$ análise sobre os resultados das simulações do primeiro e do segundo cenário apresentados na Tabela 5, quanto aos resultados encontrados sobre as mudanças nos preços domésticos ( $\mathrm{pm}$ ) para os setores agregados, é possível apontar que ambas as simulações apresentaram uma variação positiva nos preços de todos os setores, a maior delas nos setores de grãos, com um aumento, respectivamente, do primeiro e do segundo cenários de $0,76 \Delta \%$ e $1,06 \Delta \%$. Quanto às mudanças na variação dos valores das importações (viwcif) causada pela disputa comercial entre a China e os Estados Unidos, isso provocaria um aumento em todos os produtos na simulação do primeiro e do segundo cenários, exceto para os produtos do setor agregado de extração, apresentando uma variação negativa.

Para uma melhor avaliação quanto à variação na mudança dos valores das exportações ( $u x w f o b)$ para os setores do agronegócio brasileiro, é importante ana- 
lisar os dois cenários em conjunto (Gráfico 2) com a China, os Estados Unidos e o resto do mundo. Assim, identificou-se que o impacto da disputa comercial entre a China e os Estados Unidos, a partir de medidas de restrições comerciais ou medidas de protecionismos, não é benéfico para a economia de nenhum país, afetando negativamente grande parte dos setores do agronegócio, em especial para o Brasil.

Gráfico 2 - Mudança dos valores ( $\Delta \%$ ) das exportações (uxwfob) dos setores do agronegócio do Brasil, China, Estados Unidos e resto do mundo: cenários um e dois

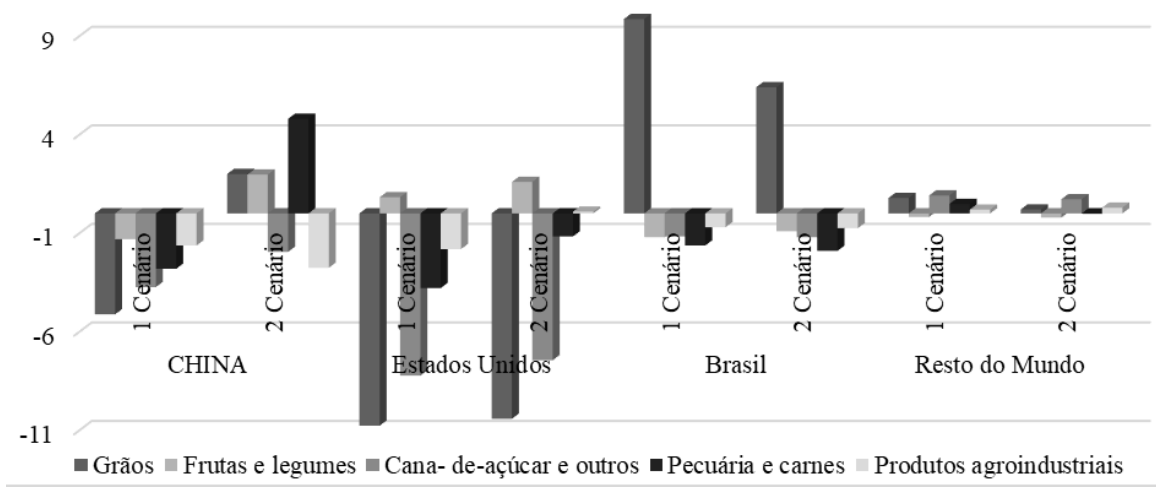

Fonte: Elaboração própria a partir do GTAP 9.

Os resultados das simulações indicam um acentuado declínio no comércio bilateral entre a China e os Estados Unidos. Como consequência disso, percebe-se uma alteração na dinâmica do comércio global, elevando as exportações de outros países, como o caso do resto do mundo, para os quais os resultados das variações apresentaram-se positivos em grande parte dos setores do agronegócio.

Os Estados Unidos, no setor de grãos, apresentam uma variação negativa nos preços das exportações de $-10,80 \Delta \%$ na primeira simulação e de $-10,42 \Delta \%$ na segunda simulação, enquanto o Brasil apresenta uma variação positiva, respectivamente, de $9,86 \Delta \%$ e $6,40 \Delta \%$. Observa-se que é possível que ocorra uma forte relação de comércio bilateral entre Brasil e China quanto ao setor de grãos, o qual foi o que apresentou impacto positivo, beneficiando-se com essa disputa comercial. No entanto, os demais setores do agronegócio, em ambos os cenários, apresentam um impacto negativo, um declínio para a economia do Brasil e dos Estados Unidos. Em geral, segundo os resultados das simulações dos cenários propostos, os impactos são negativos para a maior parte das variáveis observadas.

As tarifas comerciais implementadas entre os Estados Unidos e a China apontam um impacto negativo sobre o comércio agrícola global, em especial para o 
Brasil, evidenciando que o efeito de uma tarifa não está limitado apenas ao mercado do produto taxado ou ao país que impõe a medida. Em consonância com a teoria do comércio internacional, não há vencedores em conflitos ou disputas comerciais, pois, para ambos os países, alguns setores protegidos sob as tarifas comerciais podem ganhar, enquanto outros podem perder. Assim, tomando como referência a China e os Estados Unidos, os impactos negativos para a economia global, adquiridos no longo prazo, superam os ganhos de alguns setores no curto prazo.

\subsubsection{Análise de Sensibilidade}

Carvalho, Azevedo e Massuquetti (2019) apontam que são recorrentes as críticas aos MEGC em relação aos seus resultados serem muito sensíveis aos parâmetros de elasticidades de substituição. Não obstante a isso, uma das formas para verificar a robustez dos resultados encontrados pelos MEGC é realizar uma análise de sensibilidades nesses parâmetros.

A análise de sensibilidade envolve a simulação do mesmo cenário diversas vezes, alterando os parâmetros e as pressuposições, que podem ser determinantes para os resultados de tal cenário (GURGEL, 2013). Dessa forma, foi escolhido para este estudo verificar os parâmetros de elasticidades ESUBD, ESUBM e ESUBVA para os dois cenários simulados no estudo, apresentando os resultados encontrados pela variável endógena variação equivalente (EV), a qual indica o bem-estar (em US\$ milhões).

As variações determinadas aos parâmetros de elasticidades escolhidos, para as simulações de ambos os cenários, foram um aumento de duas vezes sobre o valor original e uma diminuição do valor original pela sua metade. Os valores originais das elasticidades de substituição apresentam-se na Tabela 1. Feijó e Steffens (2015, p. 157) explicam que fazer variar esses parâmetros para se verificar o quanto influenciam nos resultados endógenos "[...] é uma tarefa indispensável para dar credibilidade às conclusões acerca dos resultados encontrados [...]”. Assim, são apresentados os resultados da análise de sensibilidade para os dois cenários simulados na Tabela 6.

Tabela 6 - Análise de sensibilidade no bem-estar (EV) em US\$ milhões

\begin{tabular}{llllll}
\hline \multirow{2}{*}{ Região } & $\begin{array}{l}\text { Valores originais } \\
\text { simulados }\end{array}$ & $\begin{array}{l}\text { (USBD * } \mathbf{0 , 5} \\
\mathbf{e} \text { USBM *0,5) }\end{array}$ & $\begin{array}{l}\text { (USBD * 2 e } \\
\text { USBM * 2) }\end{array}$ & $(\mathbf{U S B V} * \mathbf{0 , 5})$ & $(\mathbf{U S B V} * \mathbf{2})$ \\
\hline Cenário um \\
\hline China & $-1987,82$ & $-2141,19$ & $-2703,51$ & $-2355,32$ & $-1700,17$ \\
Estados Unidos & $-3173,22$ & $-2751,44$ & $-1901,81$ & $-3155,73$ & $-3146,16$ \\
Brasil & 831,61 & 849,83 & 508,17 & 877,72 & 777,41 \\
Resto do mundo & 2899,84 & 3200,67 & 2778,52 & 3366,36 & 2455,57 \\
\hline
\end{tabular}

Continua... 
Conclusão.

\begin{tabular}{|c|c|c|c|c|c|}
\hline Região & $\begin{array}{l}\text { Valores originais } \\
\text { simulados }\end{array}$ & $\begin{array}{l}\text { (USBD * } 0,5 \\
\text { e USBM *0,5) }\end{array}$ & $\begin{array}{l}(\text { USBD * } 2 \mathrm{e} \\
\text { USBM *2) }\end{array}$ & $(U S B V * 0,5)$ & $(\mathrm{USBV} * 2)$ \\
\hline \multicolumn{6}{|l|}{ Cenário dois } \\
\hline China & $-71314,42$ & $-59811,67$ & $-60832,59$ & $-69946,05$ & $-72542,08$ \\
\hline Estados Unidos & $-40879,18$ & $-64675,61$ & $-39857,58$ & $-40576,05$ & $-41338,60$ \\
\hline Brasil & 2564,17 & 3166,33 & 1534,63 & 2486,63 & 2616,77 \\
\hline Resto do mundo & 54878,21 & 73174,39 & 36915,42 & 53400,80 & 56389,66 \\
\hline
\end{tabular}

Fonte: Elaboração própria a partir do GTAP 9.

A partir dos resultados encontrados com as simulações para a análise de sensibilidade (Tabela 6), verifica-se que os dados apresentam boa robustez, uma vez que os valores mensurados para a variável endógena de bem-estar (EV) preservaram o sentido do sinal nas diversas variações realizadas pela mudança dos parâmetros das elasticidades de substituição nos dois cenários propostos neste estudo.

A partir desta análise, é possível reafirmar que o impacto da disputa comercial entre os Estados Unidos e a China são negativos para ambas as economias, ou seja, os mais prejudicados nessa disputa comercial, em termos de bem-estar, são as suas próprias economias. Quanto ao Brasil e o resto do mundo, em ambos os cenários, mesmo com as mudanças nos valores dos parâmetros das elasticidades de substituição, continuaram apresentando ganhos de bem-estar, indicando que essa disputa comercial trará benefícios para as demais regiões.

Em consonância com esses resultados inferidos, destaca-se o estudo de Carvalho, Azevedo e Massuquetti (2019), que examinou os efeitos da disputa comercial entre Estados Unidos e China sobre os países emergentes. Os autores constatam, tanto nas simulações propostas quanto na análise de sensibilidade sobre os resultados, que, em nível global, os países envolvidos diretamente na disputa comercial, Estados Unidos e China, são os que apresentaram maiores perdas de bem-estar. Já para o Brasil, os autores evidenciaram ganhos em termos de bem-estar em todas as suas simulações.

\section{Considerações Finais}

Esta pesquisa buscou analisar os possíveis impactos no agronegócio brasileiro com a atual disputa comercial entre os Estados Unidos e a China por meio de um MEGC, com o cenário econômico de 2011. Nesse sentido, foram simulados dois cenários analíticos. O primeiro propõe simular um aumento nas tarifas de importação de 25\% sobre o aço exportado dos Estados Unidos para a China e um aumento nas tarifas de $25 \%$ sobre os produtos agrícolas (grãos, carnes e cana-de-açúcar) importados dos Estados Unidos pela China como medida retaliatória (proteção comercial parcial). O segundo cenário analisa as ações dos Estados 
Unidos ao impor um aumento de $25 \%$ nas tarifas de importação sobre todas as mercadorias obtidas da China, e a China toma medida retaliatória impondo $25 \%$ de aumento de tarifas sobre todas as mercadorias obtidas dos Estados Unidos (proteção comercial completa).

A partir do primeiro cenário, foi possível identificar que os impactos econômicos no agronegócio brasileiro foram positivos apenas para o setor de grãos, pois, na sua maioria, seriam negativos, prejudicando principalmente os setores de pecuária e carnes, cana-de-açúcar e outros, frutas e legumes e produtos agroindustriais. No segundo cenário, os impactos gerados no agronegócio brasileiro foram negativos em todos os setores, exceto no setor de grãos, impactando negativamente na variação da quantidade produzida. Dessa forma, com exceção do setor de grãos, o agronegócio brasileiro é prejudicado com a guerra comercial entre China e Estados Unidos, com efeitos negativos nos setores da pecuária e de carnes, nos quais o país possui vantagem competitiva. Esse efeito negativo vem do deslocamento de recursos produtivos (terra, capital e trabalho) dos vários setores agropecuários em direção ao setor de grãos, que é o principal setor de exportação do Brasil para a China e compete diretamente com os Estados Unidos nesse mercado.

Identificou-se, com os resultados dos indicadores de bem-estar e de crescimento da economia para os cenários propostos, que o impacto da disputa comercial é negativo para ambas as economias, enquanto que, para o Brasil e o resto do mundo, esses efeitos foram relativamente pequenos e positivos. Os efeitos no PIB dos países, considerando-se ambos os cenários simulados pelo aumento da tarifa simétrica para ambos os países, Estados Unidos e China, revelam que o impacto negativo sobre o PIB da China é maior do que o dos Estados Unidos.

Considera-se que as disputas e restrições comerciais entre países parceiros causam impactos negativos sobre suas próprias economias, assim como para toda a economia global, reduzindo o comércio internacional de bens, mercadorias e de serviços. Nesse sentido, as tarifas comerciais implementadas entre os Estados Unidos e a China apontam para um impacto negativo sobre o comércio agrícola global, em especial para o setor agronegócio do Brasil.

Ressalta-se, como limitação deste trabalho, que o MEGC usado é estático e, portanto, não captura todos os potenciais efeitos dinâmicos dessa disputa comercial entre Estado Unidos e China sobre os demais países, uma vez que, nessas disputas comerciais, pode ocorrer expansão das ideias protecionistas para outros países e regiões, prejudicando o comércio internacional multilateral como um todo. Assim, uma possível continuidade desta pesquisa seria a estimação e a investigação dos efeitos macroeconômicos e dos spillovers dessas políticas comerciais de protecionismo nas macrorregiões brasileiras, contemplando todos os setores da economia, com uma base de dados mais atual. 


\section{Referências}

AGROSTAT. Indicadores da agricultura. Disponível em: http://indicadores.agricultura.gov.br/ agrostat/index.htm. Acesso em: 24 jan. 2019.

CARVALHO, M.; AZEVEDO, A.; MASSUQUETTI, A. Emerging Countries and the Effects of the Trade War between US and China. Economies, v. 7, n. 45, p. 1-21, 2019.

COMEX STAT; MINISTÉRIO DO DESENVOLVIMENTO, INDÚSTRIA E COMÉRCIO EXTERIOR. Exportação e Importação Geral. 2018. Disponível em: http://comexstat.mdic.gov.br/pt/ geral. Acesso: 15 set. 2018.

COSTA, C. E. Notas de Microeconomia. Rio de Janeiro: Fundação Getúlio Vargas, 2008.

CURZEL, R. Mercosul: custos e benefícios de diferentes acordos comerciais. In: ENCONTRO NACIONAL DA ASSOCIAÇÃO BRASILEIRA DE RELAÇÕES INTERNACIONAIS, 3., 2011, Porto Alegre. Anais [...]. Porto Alegre, 2011. p. 1-22.

EMPRESA BRASILEIRA DE PESQUISA AGROPECUÁRIA. Soja em números, safra 2017/2018. 2018. Disponível em: https://www.embrapa.br/soja/cultivos/soja1/dados-economico. Acesso em: 24 jan. 2019.

FEIJÓ, F. T.; ALVIM, A. M. Impactos econômicos para o Brasil de um choque tecnológico na produção de etanol. Economia, v. 11, n. 3, p. 691-710, 2010.

FEIJÓ, F. T.; STEFFENS, C. Comércio internacional, alocação do trabalho e a questão da desindustrialização no Brasil: uma abordagem utilizando equilíbrio geral computável. Revista de Economia Contemporânea, Rio de Janeiro, v. 19, n. 1, p. 135-161, jan-abr/2015.

GONCALVES, S. et al. US - China Trade War: Impact Assessment. Global Trade Analysis Project, 2018. Disponível em: https://www.gtap.agecon.purdue.edu/events/Short_Courses/2018/ documents/Trade.pdf. Acesso em: 04 nov. 2018.

GTAP. Global Trade Analysis Project GTAP data bases. Disponível em: https://www.gtap. agecon.purdue.edu/databases/v9/default.asp. Acesso em: 5 fev. 2017.

GURGEL, A. C. PAEG "Hands On". 2013. In: TEIXEIRA, E. C. A.; PEREIRA, M. W. G.; GURGEL, A. C. (org.). A estrutura do PAEG. Campo Grande: Life, 2013. p. 13-26.

HERTEL, T. Global Trade Analysis: Modeling and Applications. Cambridge: Cambridge University Press, 1997.

HUFF, K. M.; HERTEL, T. W. Decomposing Welfare Changes in the GTAP Model. GTAP Technical Papers, n. 5, 2000. Disponível em: https:/www.gtap.agecon.purdue.edu/resources/ download/2365.pdf. Acesso em: 9 set. 2019.

INSTITUTO DE ESTUDO PARA O DESENVOLVIMENTO INDUSTRIAL. Novos tempos no comércio mundial: o Brasil entre China e Estados Unidos. 2019. Disponível em: https://iedi. org.br/cartas/carta_iedi_n_908.html. Acesso em: 01 mar. 2019. 
LI-CHUNDING.; HE-CHUANTIAN.; LIN-CHUANGWEI. Economic Impacts of the Possible China-US Trade War. Journal Emerging Markets Finance and Trade, v. 54, n. 7, p. 1557-1577, 2018.

LIU, Y. et al. China's Potential Cotton Tariffs and U.S. Cotton Exports: Lessons from History. Choices, v. 33, n. 2, 2018.

MINISTÉRIO DO DESENVOLVIMENTO, INDÚSTRIA E COMÉRCIO EXTERIOR. Exportação e Importação. 2018. Disponível em: http//www.mdic.gov.br/. Acesso em: 15 set. 2018.

MORETTO, L. G. et al. Integração comercial entre Brasil e China. Revista de Política Agrícola, v. 26, n. 4, p. 7-21, 2017.

OBSERVATORY OF ECONOMIC COMPLEXITY. Countries, Exports and Imports. 2018. Disponível em: https://atlas.media.mit.edu/en/profile/country/chn/. Acesso em: 29 set. 2018.

OLIVEIRA, A. R.; AZEVEDO, A. F. Z. Os Efeitos da Aliança do Pacífico sobre o Comércio e o Bem-Estar da Região e do Mercosul. Análise Econômica, v. 36, n. 70, p. 149-177, 2018.

OLIVEIRA; G. G.; MATA; H. T. C.; TEIXEIRA, E. C. Análise das Perspectivas da Revisão da Rodada do Milênio sobre o Mercado Internacional de Commodities. Revista Paraná de Desenvolvimento, n. 97, p. 49-69, 1999.

ROSYADI, S. A.; WIDODO, T. Impacts of Donald Trump's Tariff Increase against China on Global Economy: Global Trade Analysis Project (GTAP) Model. MPRA Papers, n. 79493, 2017.

SILVA, R. A. Impactos do Acordo de Preferência Comercial Transpacífico no agronegócio brasileiro. 2017. Dissertação (Mestrado em Administração) - Centro de Ciências Sociais e Humanas, Universidade Federal de Santa Maria, Santa Maria, 2017.

TAHERIPOUR, F; TYNER, W. E. Impacts of Possible Chinese 25\% Tariff on U.S. Soybeans and Other Agricultural Commodities. Choices, v. 33, n. 2, 2018.

THORSTENSEN, V. A. OMC - Organização Mundial do Comércio e as negociações sobre comércio, meio ambiente e padrões sociais. Revista Brasileira de Política Internacional, v. 41, n. 2, p. 29-58, 1998.

UNITED NATIONS CONFERENCE ON TRADE AND DEVELOPMENT. Key Statistics and Trends in Trade Policy 2018: Trade Tensions, Implications for Developing Countries. Geneva: United Nations, 2019. Disponível em: https://unctad.org/system/files/official-document/ ditctab2019d1_en.pdf. Acesso em: 01 mar. 2019.

UNITED STATES CENSUS BUREAU. Trade in goods with China. 2018. Disponível em: https:// www.census.gov. Acesso em: 22 ago. de 2018.

UNITED STATES DEPARTMENT OF AGRICULTURE. Foreign Agricultural Service. 2018. Disponível em: https://apps.fas.usda.gov/gats/default.aspx. Acesso em: 29 set. 2018. 
UNITED STATES TRADE REPRESENTATIVE. Facts about US-China Trade. 2018. Disponível em: https://ustr.gov/countries-regions/china-mongolia-taiwan/peoples-republic-china. Acesso em: 29 set. 2018.

VILELA, L. G. Relações comerciais entre Brasil e China: Uma análise de bem-estar com base em modelo de equilíbrio geral computável. São Paulo. 2012. Dissertação (Mestrado em Economia) - Escola de Economia de São Paulo, Fundação Getúlio Vargas, São Paulo, 2012.

WALMSLEY, T. L.; AGUIAR, A. A; NARAYANAN, B. Introduction to the Global Trade Analysis Project and the GTAP Data Base. GTAP Working Papers, n. 67, 2012. Disponível em: https://www.gtap.agecon.purdue.edu/resources/download/6122.pdf. Acesso em: 29 set. 2018.

WHITE HOUSE. Declarations and Highlights. Disponível em: https://www.whitehouse.gov. Acesso em: 22 ago. 2018.

WING I. S. Computable General Equilibrium Models and Their Use in Economy-Wide Policy Analysis. The MIT Joint Program on the Science and Policy of Global Change, Technical Note N. 6, 2004.

WORLD BANK. Goods Exports. Disponível em: https://data.worldbank.org/indicator/ BX.GSR.MRCH.CD?view= chart. Acesso em: 02 de set. 2018.

WORLD TRADE ORGANIZATION. World Trade Statistical Review 2018. Geneva: World Trade Organization, 2018. Disponível em: https:/www.wto.org/english/res_e/statis_e/ wts2018_e/wts2018_e.pdf. Acesso em: 03 nov. 2018.

\section{Autor correspondente:}

Elisangela Gelatti

E-mail: elisangelagelatti@hotmail.com

Recebido em: 04/06/2019.

Aceito em: 09/10/2019.

\section{(cc) BY}

Este é um artigo de acesso aberto distribuído sob os termos da Creative Commons Attribution CC-BY 4.0, que permite uso irrestrito, distribuição e reprodução em qualquer meio, desde que o trabalho original seja devidamente citado. 